\title{
Neisseria meningitidis
}

National Cancer Institute

\section{Source}

National Cancer Institute. Neisseria meningitidis. NCI Thesaurus. Code C86605.

A species of aerobic, Gram-negative, diplococci shaped bacteria assigned to the phylum Proteobacteria. This species is catalase and oxidase positive, non-hemolytic, nonpigmented, does not reduce nitrate or nitrite, does not synthesize polysaccharides, grows on blood, chocolate, or Muller-Hinton agar, and produces acid from glucose and maltose but not fructose, sucrose, mannose, or lactose. N. mening itidis, known commonly as meningococcus, is the causative agent of cerebrospinal meningitis, but is also associated with other human infections, but can be commensal in the oropharynx and nasopharynx of carriers. 